\title{
DAMPAK PERUBAHAN IKLIM TERHADAP CADANGAN \\ KARBON DAN KETERSEDIAAN AIR DI DAERAH ALIRAN SUNGAI (STUDI KASUS DI DAS COBANRONDO)
}

\author{
IMPACT OF CLIMATE CHANGE FOR CARBON RESERVE \\ AND AVAILABILITY OF WATER ON WATERSHED (CASE STUDY \\ IN DAS COBANRONDO)
}

\author{
Eko Noerhayati*), Azizah Rahmawati \\ Universitas Islam Malang, Indonesia \\ *Email:eko_unisma@ymail.com
}

\begin{abstract}
Abstrak
Kebakaran hutan telah menempatkan Indonesia dalam urutan ketiga negara penghasil emisi $\mathrm{CO}_{2}$ terbesar di dunia. Perubahan iklim sebagai implikasi pemanasan global diperkirakan akan meningkatkan intensitasnya. Penelitian ini dilakukan pada Daerah Aliran Sungai Cobanrondo yaitu meneliti perubahan iklim terhadap komponen karbon dioksida $\left(\mathrm{CO}_{2}\right)$, curah hujan, banjir dan pola distribusinya. Metode penelitian menggunakan metode survei dan pengumpulan data dari instansi terkait berupa data sekunder. Hasil penelitian menunjukan bahwa Besarnya potensi nilai karbon $\left(\mathrm{CO}_{2}\right)$ pada DAS Cobanrondo pada tataguna lahan hutan sebesar 648,83 ton/Ha dan pada tahun 1993 sebesar 603236,07 tahun 2008 sebesar 489263,89 ton. Suhu udara mempengaruhi hasil indeks kekeringan Daerah Aliran DAS Cobanrondo dengan hubungan $\mathrm{Y}=-3,7889 \mathrm{X}+149,33$.
\end{abstract}

Kata kunci: Daerah Aliran Sungai, iklim, perubahan, karbon

\begin{abstract}
Forest fires have put Indonesia in the third largest $\mathrm{CO}_{2}$ emitters in the world. This research was conducted at the Watershed Cobanrondo was researching climate change on the components of carbon dioxide $\left(\mathrm{CO}_{2}\right)$, rainfall, flooding and distribution patterns. The research method used survey methods and secondary data. The results showed that the magnitude of the potential value of carbon dioxide $\left(\mathrm{CO}_{2}\right)$ in the watershed Cobanrondo on forest land use was 648.83 tons / ha and in 1993 amounted to 603,236.07 in 2008 amounted to 489,263.89 tons. Air temperature affects the results of a drought index watershed Watershed Cobanrondo was $X+Y=-3.7889149,33$.
\end{abstract}

Keywords: watershed, Climate, change, Carbon 


\section{PENDAHULUAN}

Meningkatnya suhu global diperkirakan akan meningkatkan intensitas fenomena cuaca yang ekstrim, serta perubahan jumlah dan pola presipitasi dimana intensitas hujan akan meningkat, periode musim hujan menjadi lebih singkat dan periode musim kemarau menjadi lebih panjang. Peningkatan intensitas hujan dan musim hujan yang pendek (disebagian tempat) yang dapat mengakibatkan peningkatan intensitas dan frekuensi banjir, peningkatan potensi tanah longsor akibat kejenuhan air yang tinggi (water induced landslide), memicu terjadinya erosi dan sedimentasi. Sedangkan berkurangnya curah hujan dan bertambah panjangnya periode musim kemarau yang dapat mengakibatkan, diantaranya berkurangnya persediaan air untuk air minum, berkurangnya persediaan air untuk industri, lingkungan dan keperluan lainnya, memburuknya kualitas air disungai akibat menurunnya debit sungai pada Daerah Aliran Sungai (DAS).

Perubahan penggunaan lahan di DAS dan pertumbuhan penduduk menyebabkan tekanan yang tinggi terhadap lahan hutan. Tekanan perubahan lahan ini mengakibatkan lahan pertanian lebih intensif, pembukaan lahan hutan makin meluas, kehilangan biodiversitas lahan makin tinggi dan berdampak kepada pemanasan global. Menurut Wetland International (2006) dalam Hairiah dan Rahayu (2007), kebakaran hutan dan lahan serta gangguan lahan lainnya telah menempatkan Indonesia dalam urutan ketiga negara penghasil emisi $\mathrm{CO}_{2}$ terbesar di dunia. Menurut Tjoek Walujo Subijanto (2008) pada saat ini di DAS Kali Brantas sudah tampak perubahan-perubahan akibat terjadinya perubahan iklim antara lain adanya perubahan jumlah dan pola presipitasi yang menyebabkan meningkatnya kejadian banjir mengingat kapasitas waduk untuk menampung volume air banjir sudah semakin berkurang karena sedimentasi. Kawasan DAS Konto Hulu merupakan bagian dari DAS Brantas memiliki luasan sekitar 23.700 ha, termasuk dalam dua daerah kecamatan, yaitu Pujon dan Ngantang.. Kecamatan Pujon merupakan bagian dari wilayah timur DAS Konto Hulu. Luasan yang tergolong DAS Konto Hulu di daerah Pujon adalah sekitar 12.505 ha. Sedangkan untuk wilayah barat DAS Konto Hulu meliputi luasan 11.195 ha di Kecamatan Ngantang. Peningkatan kepadatan penduduk di DAS Konto Hulu (dari $587 \mathrm{jiwa} / \mathrm{km}^{2}$ pada tahun 1990 menjadi 1057 jiwa $/ \mathrm{km}^{2}$ pada tahun 2012 disinyalir mendorong peningktan aktivitas manusia dalam menggunakan lahan. Akibatnya terjadi alih fungsi hutan menjadi lahan pertanian. Dalam kurun waktu 1990-2012, terjadi penurunan luasan hutan yang diiringi meningkatnya luasan semak belukar dan perkebunan. Sehingga akan mempengaruhi adanya perubahan kadar $\mathrm{CO}_{2}$.

\section{Rumusan Masalah}

1. Berapa nilai cadangan karbon sesuai dengan tipe tutupan lahan di Sub Daerah Aliran Sungai Konto

2. Bagaimana Frekuensi banjir di Sub Daerah Aliran Sungai Konto

3. Bagaimana nilai kekeringan pada Sub Daerah Aliran Sungai Konto karena perubahan iklim

\section{METODE}

Ada dua tahap utama dalam melakukan penelitian ini, yaitu tahap I mencari nilai kandungan karbon berdasarkan tipe penutupan lahan yang ada pada DAS dan tahap II adalah menganalisis frekuensi banjir, perubahan dan pola presipitasi berdasarkan data iklim.

\section{Tempat Penelitian}

- Jurusan Sipil Fakultas Teknik Universitas Islam Malang

- Laboratorium Teknik Sipil Fakultas Teknik Universitas Islam Malang

Waktu penelitian dilakukan pada 2 keadaan pengamatan yaitu pada musin hujan dan pada musim kemarau.

\section{Alat yang digunakan}

1. Alat pencatat tinggi muka air otomatis (AWLR) terletak di desa Jabon yang dikelola oleh Balai Sumber Daya Air BangauGedangan Malang. 
2. Tiga alat pencatat hujan harian terletak di Kecamatan Ngantang desa Jombok dan desa Tulungrejo yang dikelola oleh Dinas Pengairan Kabupaten Malang.

3. Current meter untuk mengukur kecepatan air di sungai.

4. GPS yang digunakan untuk mengetahui perubahan tataguna lahan.

\section{Metode Pengambilan Data}

Metode pengumpulan data pada peneliti pelitian ini menggunakan pendekatan metode survei, yaitu perolehan data dilakukan dengan cara langsung dikumpulkan dari sumber pertama atau pengukuran langsung di lapangan (data primer) dan dari instansi terkait atau secara tidak langsung (data sekunder).

\section{Peta Topografi dan Lahan}

Peta topografi yang digunakan adalah skala 1:25.000 dari Perum Jasatirta I. Sedangkan peta tata guna lahan, peta batas DAS dan jaringan sungai (skala 1:25.000) diperoleh dari Balai Pengelolaan DAS Brantas.
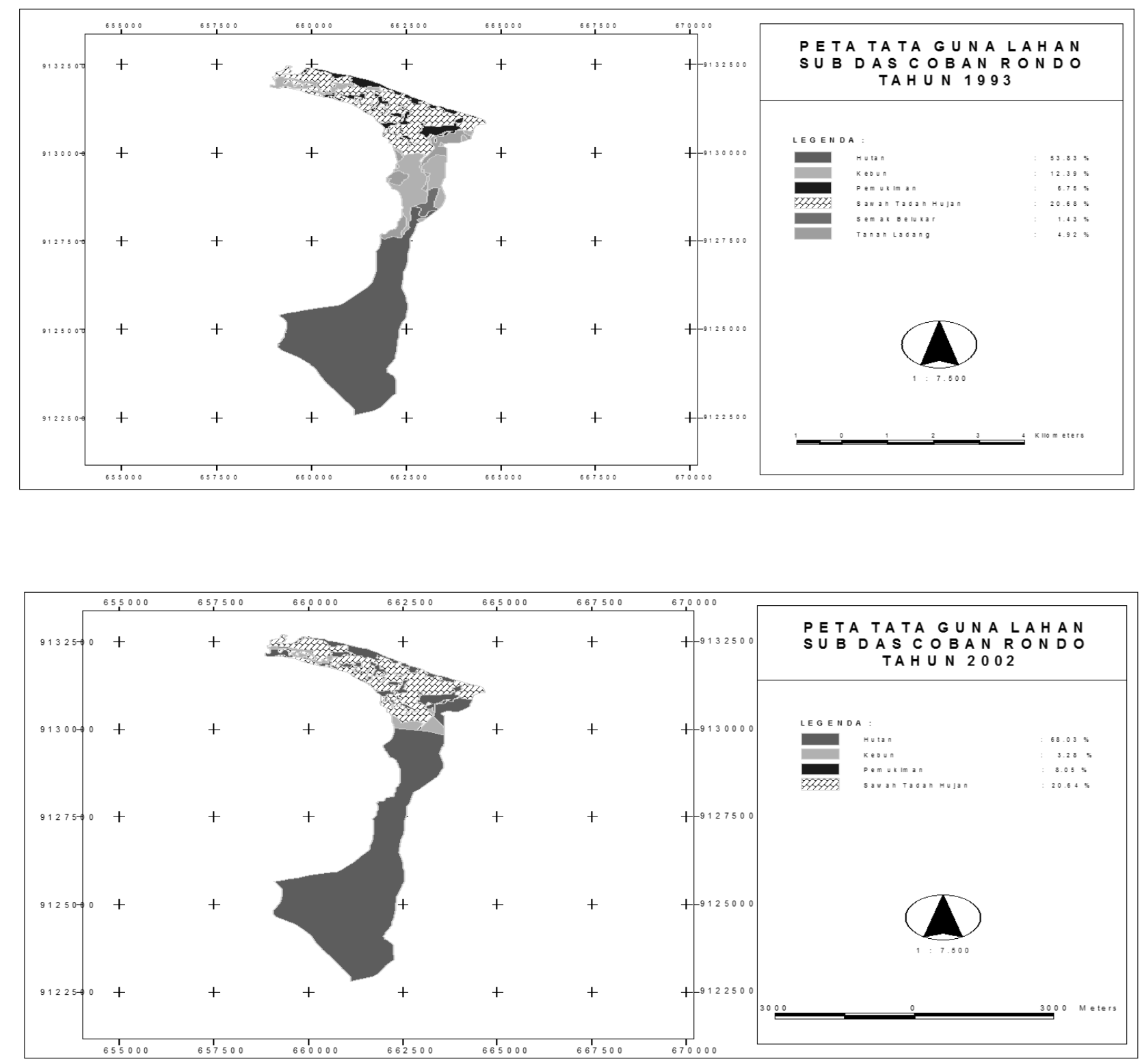

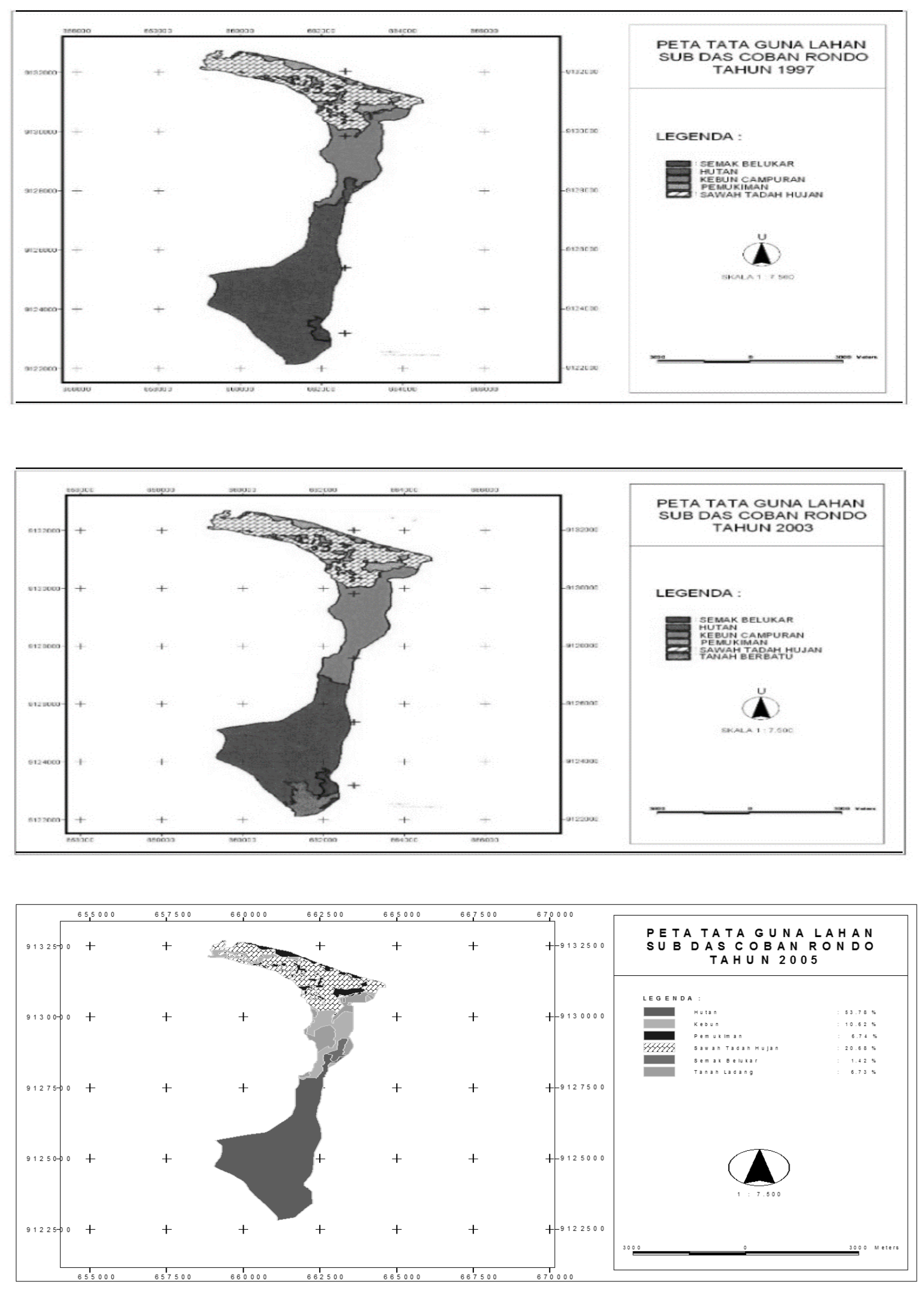

Gambar 1. Perubahan Tata Guna Lahan DAS Cobanrondo 


\section{HASIL DAN PEMBAHASAN}

\section{Uji Konsistensi Data Hujan}

Uji konsistensi data dilakukan dengan menggunakan kurva massa ganda (double mass curve) Berikut ini adalah hasil perhitungan uji konsistensi data di Stasiun Kedungrejo dan Stasiun Pujon.

Tabel 1. Uji Konsistensi Data Hujan Stasiun Kedungrejo dan Stasiun Pujo

\begin{tabular}{crrrr}
\hline & \multicolumn{2}{c}{ St. Kedurejo } & \multicolumn{2}{c}{ St.Pujon } \\
\cline { 2 - 5 } Tahun & Curah Hujan $(\mathbf{m m})$ & Komulatif $(\mathbf{m m})$ & $\begin{array}{c}\text { Curah Hujan } \\
(\mathbf{m m})\end{array}$ & $\begin{array}{c}\text { Komulatif } \\
(\mathbf{m m})\end{array}$ \\
\hline$[1]$ & {$[2]$} & {$[3]$} & {$[4]$} & {$[5]$} \\
1994 & 1629 & 1629 & 2335 & 2335 \\
1995 & 2347 & 3976 & 2271 & 4606 \\
1996 & 1896 & 5872 & 1896 & 6502 \\
1997 & 1307 & 7179 & 1307 & 7809 \\
1998 & 2475 & 9654 & 2475 & 10284 \\
1999 & 2431 & 12085 & 2755 & 13039 \\
2000 & 1720 & 13805 & 1552 & 14591 \\
2001 & 2387 & 16192 & 2514 & 17105 \\
2002 & 2436 & 16628 & 4221 & 17526 \\
2003 & 1855 & 18483 & 2386 & 19510 \\
2004 & 2219 & 20702 & 1630 & 21896 \\
2005 & 1499 & 22201 & 1910 & 23526 \\
2006 & 2063 & 24264 & 2372 & 25436 \\
2007 & 2503 & 26767 & 2375 & 27808 \\
2008 & 2423 & 29190 & 2064 & 30183 \\
2009 & 2127 & 31317 & 3504 & 32247 \\
2010 & 3063 & 34380 & 2266 & 35751 \\
2011 & 2421 & 36801 & 2110 & 38017 \\
2012 & 2038 & 38839 & 3624 & 40127 \\
2013 & 3112 & 41951 & 2694 & 43751 \\
2014 & 2257 & 44208 & & 46445 \\
\hline
\end{tabular}

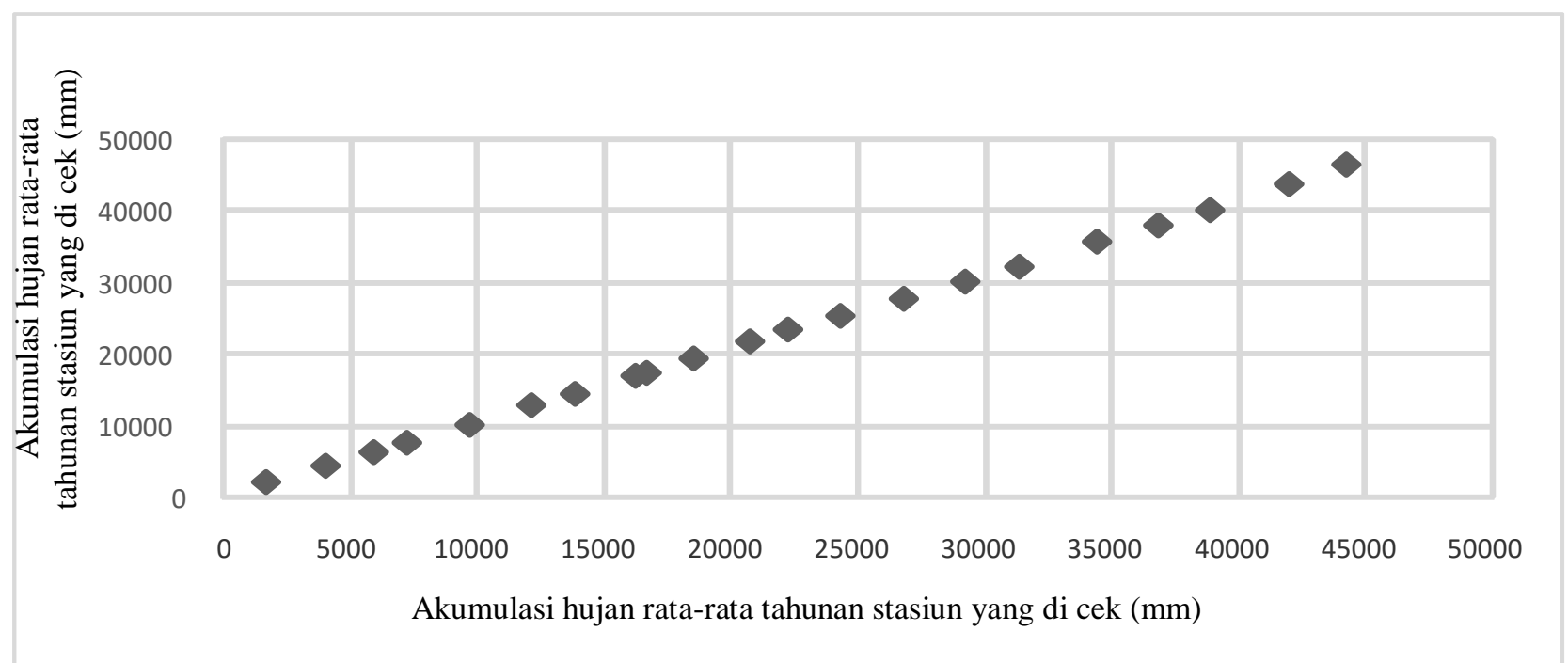

Gambar 2. Lengkung Massa Ganda 
Tabel 2. Data Debit Bulanan DAS Coban Rondo

\begin{tabular}{|c|c|c|c|c|c|c|c|c|c|c|c|c|c|}
\hline \multirow{2}{*}{ Tahun } & \multicolumn{12}{|c|}{ Bulan } & \multirow{2}{*}{$\begin{array}{c}\text { Tahunan } \\
\text { Total }\end{array}$} \\
\hline & Jan & Feb & Mar & Apr & Mei & Jun & Jul & Ags & Sept & Okt & Nop & Des & \\
\hline 1993 & 0,85 & 1,02 & 0,48 & 0,48 & 0,33 & 0,44 & 0,32 & 0,29 & 0,29 & 0,24 & 0,39 & 0,59 & 0,59 \\
\hline 1997 & 0,80 & 0,63 & 0,20 & 0,13 & 0,13 & 0,12 & 0,12 & 0,12 & 0,13 & 0,12 & 0,13 & 0,20 & 2,83 \\
\hline 2002 & 0,74 & 1,31 & 0,89 & 0,69 & 0,55 & 0,47 & 0,34 & 0,34 & 0,33 & 0,23 & 0,31 & 0,62 & 6,82 \\
\hline 2003 & 0,57 & 1,19 & 0,67 & 0,33 & 0,74 & 0,333 & 0,36 & 0,30 & 0,27 & 0,56 & 0,61 & 0,63 & 6,56 \\
\hline 2005 & 0,21 & 0,23 & 0,30 & 0,25 & 0,14 & 0,19 & 0,20 & 0,21 & 0,34 & 0,46 & 0,46 & 0,58 & 3,57 \\
\hline 2006 & 0.50 & 0.49 & 0.41 & 0.51 & 0.57 & 0.32 & 0.30 & 0.16 & 0.08 & 0.06 & 0.06 & 0.17 & 3,63 \\
\hline 2008 & 0.64 & 1.10 & 1.40 & 1.05 & 0.86 & 0.52 & 0.27 & 0.21 & 0.25 & 0.43 & 1.01 & 0.96 & 8,68 \\
\hline Max & 0,85 & 1,31 & 1,40 & 1,05 & 0,86 & 0,52 & 0,36 & 0,34 & 0,34 & 0,56 & 1,01 & 0,96 & 8,68 \\
\hline Min & 0,21 & 0,23 & 0,2 & 0,13 & 0,13 & 0,12 & 0,12 & 0,12 & 0,08 & 0,06 & 0,06 & 0,17 & 2,83 \\
\hline Rerata & 0,62 & 0,85 & 0,62 & 0,49 & 0,47 & 0,34 & 0,27 & 0,23 & 0,24 & 0,30 & 0,42 & 0,54 & 5,40 \\
\hline
\end{tabular}

\section{Analisa Frekuensi Banjir DAS Coban Rando}

Nilai curah hujan rancangan diperoleh dengan menggunakan rumus Log Perason Tipe III.

\section{Analisa Debit Limpasan}

Penentuan besarnya debit limpasan metode rasional modifikasi di sungai Lesti digunakan rumus persamaan debit limpasan rasional modifikasi (Suripin, 2003) yaitu :

$\mathrm{Q}=0.278$.C. I. A

Dimana :

$\mathrm{Q}=\operatorname{Debit}\left(\mathrm{m}^{3} /\right.$ detik$)$

$\mathrm{C}=$ Koefisien Aliran Permukaan

I = Intensitas Hujan ( $\mathrm{mm} / \mathrm{jam})$

A $=$ Luas Daerah Pengaliran $\left(\mathrm{Km}^{2}\right)$

$>\quad$ Luas Lahan DAS Cobanrondo $=1682,516 \mathrm{Ha}=168,2516 \mathrm{Km}^{2}$

$>\quad$ Nilai $\mathrm{C}_{\text {rata-rata didapatkan }}=0,2$

Perhitungan debit limpasan permukaan adalah sebagai berikut: $\begin{aligned} \mathrm{Q}_{2} & =0,00278 \times 0,2 \times 11,59 \times 168,2516 \\ & =1,0845 \mathrm{~m}^{3} / \mathrm{det}\end{aligned}$

Q5 $=0,00278 \times 0,2 \times 16,32 \times 168,2516$
$=1,5271 \mathrm{~m}^{3} / \mathrm{det}$

$$
\begin{aligned}
\mathrm{Q}_{10} & =0,00278 \times 0,2 \times 19,63 \times 168,2516 \\
& =1,8369 \mathrm{~m}^{3} / \mathrm{det} \\
\mathrm{Q}_{25} & =0,00278 \times 0,2 \times 24,16 \times 168,2516 \\
& =2,2608 \mathrm{~m}^{3} / \mathrm{det} \\
\mathrm{Q}_{50} & =0,00278 \times 0,2 \times 28,36 \times 168,2516 \\
& =2,6538 \mathrm{~m}^{3} / \mathrm{det} \\
\mathrm{Q}_{100} & =0,00278 \times 0,2 \times 31,83 \times 168,2516 \\
& =2,9785 \mathrm{~m}^{3} / \mathrm{det}
\end{aligned}
$$

\section{Nilai Indeks Kekeringan}

Berikut adalah nilai Indeks Kekeringan Hutan DAS Coban Rondo. Indeks kekeringan hutan Coban rondo dapat dilihat pad Tabel 3.

Tabel 3. Tabel Indeks Kekeringan dan Suhu rata-rata maksimum

\begin{tabular}{lrr}
\hline Tahun & $\begin{array}{r}\text { Suhu rata-rata } \\
\text { maksimum }\end{array}$ & IK Hutan \\
\hline 1993 & 34.9 & 16.61 \\
1997 & 29.6 & 47.37 \\
2002 & 30.1 & 30.95 \\
2003 & 30.4 & 33.81 \\
2005 & 30.2 & 24.83 \\
2006 & 31.8 & 33.85 \\
\hline
\end{tabular}


Tabel 4 Luas Tata Guna Lahan Sub DAS Coban Rondo

\begin{tabular}{crrrrrr}
\hline Tata Guna Lahan & $\mathbf{1 9 9 3}$ & $\mathbf{1 9 9 7}$ & $\mathbf{2 0 0 2}$ & $\mathbf{2 0 0 3}$ & $\mathbf{2 0 0 5}$ & $\mathbf{2 0 0 6}$ \\
\hline Hutan & 929.729 & 929.208 & $1,057.021$ & 784.651 & 928.912 & 929.085 \\
Kebun & 291.305 & 291.508 & 164.213 & 436.582 & 290.941 & 292.085 \\
Permukiman & 113.523 & 113.598 & 114.702 & 114.702 & 114.702 & 114.916 \\
Sawah & 347.9588 & 348.202 & 227,690 & 346.579 & 347.959 & 346.430 \\
Luas (Ha) & 1.682 .516 & 1.682 .516 & 1.682 .516 & 1.682 .514 & 1.682 .514 & 1.682 .516 \\
\hline
\end{tabular}

Tabel 5 Perhitungan Nilai Karbon Hutan

\begin{tabular}{rcrcr}
\hline Tahun & $\begin{array}{c}\text { Tutupan } \\
\text { Lahan }\end{array}$ & Luas (Ha) & $\begin{array}{c}\text { Rata-rata } \\
\text { Potensi Karbon Hasil Sampling }\end{array}$ & Total Stok Karbon \\
\hline 1993 & Hutan & 929.729 & 648,83 ton/ha & $60.3236,07$ \\
1997 & Hutan & 929.208 & 648,83 ton/ha & $60.2898,03$ \\
2002 & Hutan & 1.057 .021 & 648,83 ton/ha & $68.5826,94$ \\
2003 & Hutan & 784.651 & 648,83 ton/ha & $50.9105,11$ \\
2005 & Hutan & 928.912 & 648,83 ton/ha & $60.2705,97$ \\
2006 & Hutan & 929.085 & 648,83 ton/ha & $60.2818,22$ \\
2008 & Hutan & 754,071 & 648,83 ton/ha & $48.9263,89$ \\
\hline
\end{tabular}

Secara umum DAS Cobanrondo telah banyak mengalami perubahan lahan terutama pada lahan hutan yang nantinya sangat berpengaruh terhadap ketersediaan cadangan karbon di lahan.

\section{KESIMPULAN}

Hasil penelitian menunjukan bahwa Besarnya potensi nilai karbon $\left(\mathrm{CO}_{2}\right)$ pada DAS Cobanrondo pada tataguna lahan hutan sebesar 648,83 ton/Ha dan potensi nilai total karbon pada DAS Cobanrondo makin tahun menurun yaitu pada tahun 1993 sebesar 603236,07 ton dan pada tahun 2008 sebesar 489263,89 ton.

Suhu udara mempengaruhi hasil indeks kekeringan Daerah Aliran Cobanrondo dengan hubungan $\mathrm{Y}=-3,7889 \mathrm{X}+149,33$.

\section{DAFTAR PUSTAKA}

Arsyad, S. 2000. Konservasi Tanah dan Air. IPB Press. Bogor
Asdak, C. 2002. Hidrologi dan Pengelolaan Daerah Aliran Sungai (edisi kedua). Gajah Mada University Press. Yogyakarta.

Dharmawati, ND., Darmadi, dan Sudira, P. 2002. Aplikasi Model Bilangan KurvaSCS Untuk Memprediksi Limpasan Permukaan (Studi Kasus Di Daerah Aliran Sungai Bengawan Solo Hulu). Jurnal Agrosains, 15(1). ISSN 14116170. Program Pascasarjana Universitas Gajah Mada. Yogyakarta.

Hana, D. E. 2006. Model Hidrograf satuan Sintetis Berdasarkan Pendekatan Hidrograf Satuan Pengamatan. Jurusan Pengairan Universitas Brawijaya. Malang.

Ilyas, MA dan Effendy, R. 1993. Banjir Di Jambi dan Kaitannya dengan Kerusakan DAS Batanghari. Jurnal Penelitian dan Pengembangan Pengairan, ISSN 0215- 
1111. Pusat Penelitian Dan Pengembangan Pengairan. Bandung.

Mastra, AB., Suriyadi J., Suryanto, D., Soerjamihardja, S., Lestari, dan Haryono. 1994. Pengkajian Penggunaan Citra Inderaja Untuk Evaluasi Banjir DAS Tulangbawang Lampung. Jurnal Ilmiah Geomatika, 1(2), ISSN 08542759. Bakorsurtanal. Bogor.

Rahayu, S. 2007. Perubahan Iklim dan Kemiskinan: Bagaimana nasib petani kecil Indonesia kedepan. Kongres Ilmu Pengetahuan Nasional IX (KIPNAS-IX). Jakarta.

Runtunuwu, E dan Syahbuddin, H. 2007. Perubahan Pola Curah Hujan dan Dampaknya Terhadap Periode Masa Tanam. Balai Besar Penelitian dan Pengembangan Sumber Daya Lahan Pertanian. Bogor.

Siswoyo, H. 2001. Pengembangan Model Hidrograf Satuan Sintetis Snyder Untuk Sungai-sungai di Jawa Timur. Tesis Magister Teknik. Institut Teknologi Sepuluh Nopember Surabaya.

Siswoyo, H. dan S.Y. Arini. 2001. Model Hidrograf Satuan Sintetis Untuk Perkiraan Banjir di Satuan Wilayah Sungai (SWS) Pekalen Sampean dan Satuan Wilayah Sungai (SWS) Bengawan Solo. Jurnal Teknik, 8(3), pp. 27-34. Fakultas Teknik Universitas Brawijaya. Malang.

Siswoyo, H. dan T. Kadri. 2003. Memanfaatkan Interprestasi Hasil Pengukuran AWLR Untuk Memantau Keberhasilan Pengelolaan Daerah Aliran Sungai. Prosiding Pertemuan Ilmiah Tahunan Himpunan Ahli Teknik Hidraulik (PIT HATHI) XX. Samarinda.

Siswoyo, H. 2003. Optimasi Penggunaan Lahan Dalam Pengelolaan DAS Dengan
Pendekatan Aspek Hidrologi Berdasarkan Teori Hidrograf Satuan Sintetis US SCS. Kumpulan Makalah Ilmiah Pengantar Falsafah Sains. Institut Pertanian Bogor.

Siswoyo, H. 2003. Pengelolaan dan Pelestarian Sumberdaya Air. Makalah Topik Khusus Program Doktor. Program Studi Ilmu Pengelolaan Daerah Aliran Sungai, Program Pascasarjana, Institut Pertanian Bogor. (tidak diterbitkan). Bogor.

Soemarto, CD. 1986. Hidrologi Teknik. Usaha Nasional. Surabaya.

Sosrodarsono, Suyono dan Takeda, Kensaku. 1980. Hidrologi untuk Pengairan. PT. Pradnya Paramita. Jakarta.

Salisbury, F. B. and C.W. Ross. 1995. Fisiologi Tumbuhan. Jilid I. Penerbit ITB. Bandung.

Syarifuddin, M. 2011. Dampak Perubahan Iklim Bagi Pertumbuhan dan Perkembangan Tanaman. Program Studi Manajemen Pertanian lahan Kering Politeknik Pertanian Negeri Kupang. Kupang. http://programstudimplk.blogsp ot.com/2011/05/dampak-perubahaniklim-bagi-pertumbuhan.html. [Diakses 16 Januari 2012].

Tang, R. S., Zheng, J. C. and Zhang, D. D. 2006. The effects of high temperatures on pollen vitality and seed setting of different rice varieties. Jiangsu J. Agric. Sci. 22:369-373.

Tim Sintesis Kebijakan. 2008. Dampak Perubahan Iklim Terhadap Sektor Pertanian, Serta Strategi Antisipasi dan Teknologi Adaptasi. Balai Besar Penelitian dan Pengembangan Sumberdaya Lahan Pertanian. Bogor.

http://pustaka.litbang.deptan.go.id/publikasi/ip0 12086.pdf [Diakses 16 Januari 2012]. 